\title{
Genomic characterization of a liberibacter present in an ornamental rutaceous tree, Calodendrum capense, in the Western Cape province of South Africa. Proposal of 'Candidatus Liberibacter africanus subsp. capensis'
}

\author{
Monique Garnier, ${ }^{1}$ Sandrine Jagoueix-Eveillard, ${ }^{1}$ Pieter R. Cronje, ${ }^{2}$ \\ Hennie F. Le Roux ${ }^{3}$ and Joseph Marie Bové
}

Author for correspondence: Monique Garnier. Tel: +335568431 49. Fax: + 33556843159 .
e-mail: garnier@bordeaux.inra.fr

1 Laboratoire de Biologie Cellulaire et Moléculaire INRA \& Université Victor Ségalen Bordeaux 2, Institut de Biologie Végétale Moléculaire BP 81, 33883 Villenave d'Ornon cedex, France

2 South African Sugar Association Experiment Station, Private Bag X02, Mount Edgecombe 4300 KwaZulu-Natal, South Africa

3 Capespan International Ltd, PO Box 28, Nelspruit 1200 , Mpumalanga, South Africa

\begin{abstract}
In 1994, the uncultured phloem-restricted bacteria of citrus huanglongbing (exgreening) disease in Asia and Africa were characterized as 'Candidatus Liberobacter asiaticum' and 'Candidatus Liberobacter africanum', respectively. Following the rules of the International Code of Nomenclature of Bacteria, the two bacterial species have now been renamed ' Candidatus Liberibacter asiaticus' and 'Candidatus Liberibacter africanus'. A third liberibacter was detected by PCR in an ornamental rutaceous tree, Cape chestnut (Calodendrum capense), in South Africa. The new liberibacter was characterized by serology and from the sequences of its 165 rDNA, intergenic 16S/23S rDNA and ribosomal protein genes of the $\beta$ operon. Phylogenetic analysis showed that the liberibacter present in C. capense differed from the two previously described liberibacter species from citrus and that it was more closely related to 'Candidatus Liberibacter africanus' than to 'Candidatus Liberibacter asiaticus'. It is proposed that the liberibacter from $C$. capense be assigned a subspecies status, ' Candidatus Liberibacter africanus subsp. capensis'.
\end{abstract}

Keywords: huanglongbing, phylogeny, citrus, phloem, 'Candidatus Liberibacter africanus subsp. capensis'

\section{INTRODUCTION}

Huanglongbing (HLB) (ex-greening) is one of the most destructive diseases of citrus. The uncultured bacterium associated with the disease was characterized in 1994 from its $16 \mathrm{~S}$ rDNA sequence and shown to be a new genus in the $\alpha$-Proteobacteria (Jagoueix et al., 1994). The 'Candidatus' generic name 'Liberobacter', as defined by Murray \& Schleifer (1994), was given to the bacterium. Two species, 'Candidatus Liberobacter asiaticum' and 'Candidatus Liberobacter africanum', were described on the basis of gene sequences from the

\footnotetext{
Abbreviations: HLB, huanglongbing; IF, immunofluorescence.
}

The GenBank accession number for the 16S rDNA sequence of the Calodendrum capense bacterium, 'Candidatus Liberibacter africanus subsp. capensis', is AF137368.
rplKAJL-rpoBC operon ( $\beta$ operon) of African and Asian liberobacters (Jagoueix et al., 1994). Another 16S rDNA sequence of a 'Candidatus Liberobacter sp.' strain Okinama has recently been deposited in GenBank (accession no. AB008366; T. Iwanami, unpublished results). Following the Rules of the International Code of Nomenclature of Bacteria (Lapage et al., 1992; Trüper, 1999), stating that 'bacter' is of masculine gender and that the connecting vowel should be ' $\mathrm{i}$ ' when the preceding term is of Latin origin, the nomenclature of the two species is now revised, the two species thus becoming 'Candidatus Liberibacter asiaticus' and 'Candidatus Liberibacter africanus'.

HLB was reported to be present in the eastern and western parts of the former Transvaal province (now 
North West and Mpumalanga provinces) of South Africa as early as 1929 (Aubert et al., 1988; Da Graça, 1991; Oberholzer et al., 1965; Van de Merwe \& Andersen, 1937), where it was shown to be transmitted by the citrus psyllid Trioza erytreae (McLean \& Oberholzer, 1965). The psyllid was also abundant in other citrus-growing areas of South Africa, but the disease was not present. Thus, strong quarantine measures were applied to prevent movement of citrus from the former Transvaal province to other citrusgrowing regions of the country. In Africa, HLB and the psyllid vector are restricted to cool areas, as both $T$. erytreae and 'Candidatus Liberibacter africanus' are susceptible to temperatures higher than $25 / 30{ }^{\circ} \mathrm{C}$ (Bové et al., 1974). In 1995, symptoms of leaf mottle resembling those of HLB were observed on clementine and lemon trees in the Western Cape province of South Africa (Garnier et al., 1999). When symptomatic leaves were tested by PCR with primers specific for the liberibacters (Hocquellet et al., 1999; Jagoueix et al., 1996) 'Candidatus Liberibacter africanus' could be detected (Garnier et al., 1999). Bordering the orchard where the disease was first reported, an ornamental rutaceous tree, Cape chestnut (Calodendrum capense), also showed leaf mottle symptoms. When tested for the presence of liberibacter, positive PCR reactions were obtained (Garnier et al., 1999). In another location, a second Cape chestnut showed similar symptoms and gave also a positive PCR result. Thus, Cape chestnut was suspected to be responsible for the introduction of the HLB bacterium into the Western Cape area. Calodendrum and Citrus are two genera in the family Rutaceae, but they are phylogenetically distant. However, T. erytreae, the citrus psyllid, has been reported to feed on $C$. capense, on which it lays eggs, but nymph development does not take place (Moran, 1968).

As it is important to evaluate the role of $C$. capense in the outbreak of HLB disease in the Western Cape region, the liberibacter-like bacterium present in the $C$. capense tree was phylogenetically characterized by sequencing the $16 \mathrm{~S}$ rDNA, the intergenic $16 \mathrm{~S} / 23 \mathrm{~S}$ region and part of the rplKAJL-rpoBC operon. Comparisons with the equivalent genes from 'Candidatus Liberibacter africanus' and 'Candidatus Liberibacter asiaticus', the two liberibacter species that have been found in citrus so far, showed that the symptomatic $C$. capense tree was indeed infected with a liberibacter species, although this species differed from the two previously described ones. The $C$. capense liberibacter was more closely related to 'Candidatus Liberibacter africanus' than to 'Candidatus Liberibacter asiaticus'. It is proposed that the liberibacter present in C. capense be assigned a 'Candidatus' subspecies name, 'Candidatus Liberibacter africanus subsp. capensis'. An oligonucleotide defined from the ribosomal protein DNA sequence of this new species has been determined for its specific identification. A preliminary short report of part of these results has been published as a short communication (Garnier et al., 1999).

\section{METHODS}

Plant material. Healthy Citrus plants or Citrus plants infected with 'Candidatus Liberibacter africanus' were maintained in a glasshouse at $25^{\circ} \mathrm{C}$ during the day and at $20^{\circ} \mathrm{C}$ at night. Citrus plants infected with 'Candidatus Liberibacter asiaticus' were kept in a greenhouse at $30^{\circ} \mathrm{C}$ during the day and $25^{\circ} \mathrm{C}$ at night.

Leaves from Citrus with or without symptoms of HLB, and leaves of four $C$. capense, with or without mottle were collected in the Western Cape province of South Africa. Two of the symptomatic $C$. capense trees were growing next to an HLB-infected citrus orchard. The symptomless $C$. capense leaves were from a large tree in the botanical garden in Cape Town.

Leaves were kept in plastic bags and tested in South Africa or sent by express mail for testing in the laboratory in Bordeaux, France. Upon arrival, midribs were excised and DNA was extracted for PCR analysis.

Serological reagents. mAbs $14 \mathrm{~A} 1$ and $10 \mathrm{H} 8$ obtained against strain Nelspruit (South Africa) of 'Candidatus Liberibacter africanus' (Gao et al., 1993), and mAbs 10A6 and 2D12 against strain Poona (India) (Garnier et al., 1987), and mAbs 10F4, 5H10, 12E12 and $11 \mathrm{H} 6$ against strain Fuzhou (China) (Gao et al., 1993) of 'Candidatus Liberibacter asiaticus' were used for immunofluorescence (IF) reactions as described previously (Garnier et al., 1987).

Preparation of leaf extracts and PCR. For DNA extraction, the leaf midribs were worked up according to the Wizard purification procedure of Jagoueix et al. (1996). Extracts $(2 \mu \mathrm{l})$ were used for PCR as described previously with primers OA1, OI1 and OI2c for amplification of $16 \mathrm{~S}$ rDNA (Jagoueix et al., 1996). PCR amplification of part of the $\beta$ ribosomal protein operon (Hocquellet et al., 1999, Planet et al., 1995) was carried out with primers A2 (5'-TATAAAGGTTGACCTTTCGAGTTT-3') and J5 (5'-ACAAAAGCAGAAATAGCACGAACAA-3') with the following programme: 35 cycles each at $92{ }^{\circ} \mathrm{C}$ for $20 \mathrm{~s}, 62{ }^{\circ} \mathrm{C}$ for $20 \mathrm{~s}$, $72^{\circ} \mathrm{C}$ for $40 \mathrm{~s}$. PCR amplification was also carried out with primers 1897/1898 as described previously (Planet et al., 1995). Following amplification, $8 \mu$ laliquots of each reaction mixture were analysed by electrophoresis on $0.7 \%$ agarose gels.

Restriction enzyme analysis of amplified DNA. Twelve microlitres of A2/J5 PCR-amplified DNA were digested with $10 \mathrm{U} A p o \mathrm{I}, H i n \mathrm{f}$ or $A c i$ I restriction enzyme in a final volume of $35 \mu \mathrm{l}$ according to the manufacturer's instructions. The digested DNA was analysed by electrophoresis on $2.5 \%(\mathrm{w} / \mathrm{v})$ agarose gels. Digestion of amplified 16S rDNA with XbaI was done according to Jagoueix et al. (1996).

Cloning and sequencing PCR products. PCR-amplified DNA $(80 \mu \mathrm{l})$ was electrophoresed on a $0 \cdot 8 \%$ agarose gel. The band at the correct size was cut out of the gel and purified with the Cleanmix kit (Talent) according to the manufacturer's instructions. The DNA was eluted in $20 \mu \mathrm{l}$ water and $7 \mu 1$ solution was used for ligation in the pGEM-T easy vector (Promega). Two microlitres of the recombinant plasmid was used to transform competent $E$. coli cells by electroporation.

Plasmids were prepared with the Plasmix kit (Talent) and digested with EcoRI to determine the size of the insert. The inserts from three different plasmids were sequenced using the T7 sequencing kit (Pharmacia). 
Data analysis. Sequences were compared to those in the NCBI database using the Basic Local Alignment Search Tool (BLAST) algorithm to identify closely related sequences. Multiple sequence alignments were performed using the CLUSTAL software. Phylogenetic studies were done with PHYLIP software. The tree was constructed using the following 16S rDNA sequences (accession numbers are given in parentheses): Phyllobacterium rubiacearum strain IAM 13587 (D12790); Sinorhizobium medicae strain A321 ${ }^{\mathrm{T}}$ (L39882); Bartonella clarridgeiae strain ATCC 51734 (89208); Rochalimaea elizabethae (L01260); 'Candidatus Liberibacter asiaticus' strain Poona (L22532); 'Candidatus Liberibacter africanus' strain Nelspruit (L22533); and 'Candidatus Liberibacter sp.' strain Okinama (T. Iwanami, unpublished results) (AB008366).

\section{RESULTS}

PCR amplification of liberibacter 16S rDNA and ribosomal protein genes from Citrus sp. and C. capense leaf midribs

Primers OA1/OI2c specific for the amplification of liberibacter 16S rDNA were used with DNA from Citrus or C. capense in the Western Cape region of South Africa. An amplified product of the expected size (1160 bp) was observed with DNA extracted from HLB-affected citrus leaves as well as from mottled leaves of $C$. capense. No DNA band was obtained from the PCR tubes used as negative controls and containing either water or DNA extracted from healthy citrus and $C$. capense leaves. Similarly, the samples that gave positive PCR results with primers OA1/OI2c also gave positive reactions (680 bp band) when primers $\mathrm{A} 2 / \mathrm{J} 5$, specific for the amplification of liberibacter ribosomal protein genes, were used for PCR. No DNA band was observed in the PCR tubes used as negative controls.

\section{Sequence of the 16S rDNA of the liberibacter from C. capense and phylogenetic analysis}

The sequence of the 16S rDNA of the $C$. capense bacterium was determined (GenBank accession no. AF137368).

The 16S rDNA sequences of the liberibacters, the $C$. capense bacterium and other bacteria present in databases were used for phylogenetic analysis. Fig. 1 presents the phylogenetic tree constructed by using the distance matrix method. It shows that the liberibacters and the $C$. capense bacterium cluster together. The $C$. capense bacterium is more closely related to 'Candidatus Liberibacter africanus' (97.4\% homology) than to 'Candidatus Liberibacter asiaticus' (96.9\% homology) and, upon digestion of the DNA amplified from symptomatic $C$. capense with $X b a \mathrm{I}$ (Jagoueix et al., 1996), the restriction profile was that of 'Candidatus Liberibacter africanus' (result not shown). However, the 16S rDNA sequences of the $C$. capense liberibacter and 'Candidatus Liberibacter africanus' were not identical.

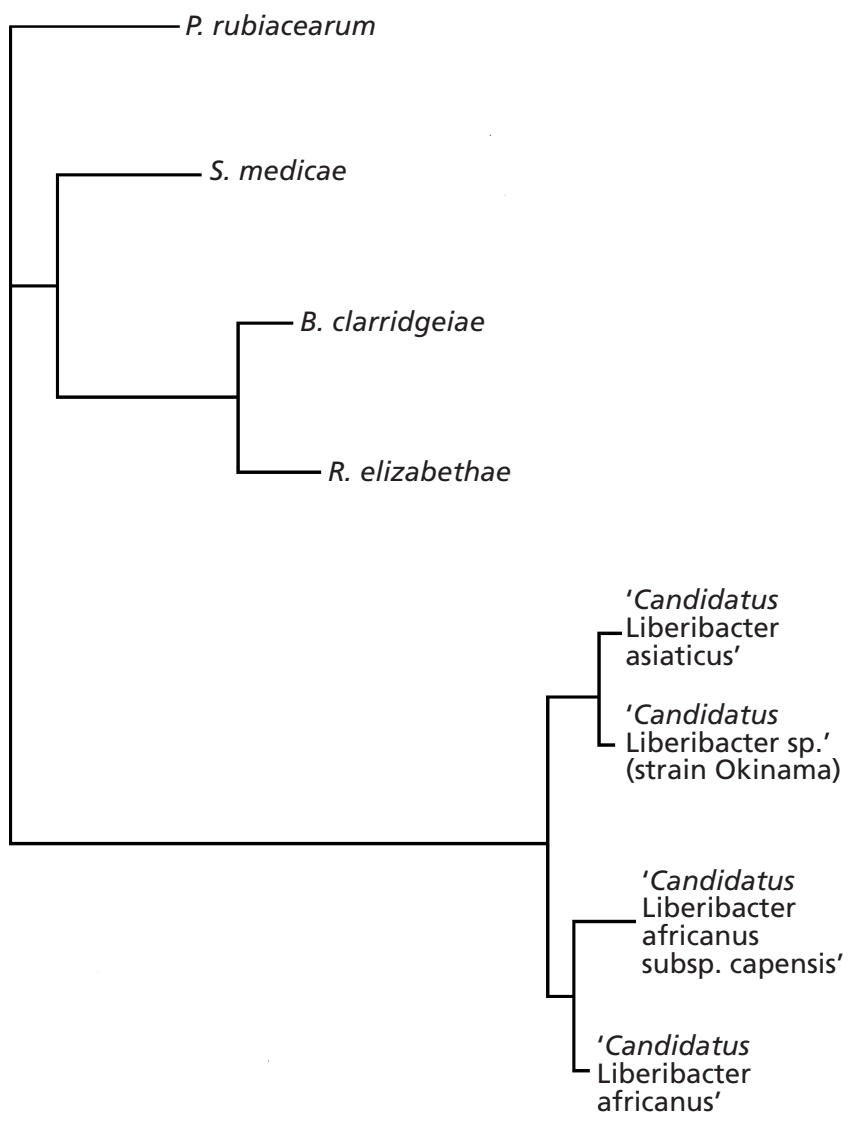

0.01

Fig. 1. Phylogenetic tree constructed with $16 \mathrm{~S}$ rDNA sequences obtained from GenBank (accession numbers in parentheses): Phyllobacterium rubiacearum strain IAM 13587 (D12790);

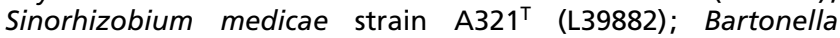
clarridgeiae strain ATCC 51734 (89208); Rochalimaea elizabethae (L01260); 'Candidatus Liberibacter asiaticus' strain Poona (L22532); 'Candidatus Liberibacter africanus' strain Nelspruit (L22533); and 'Candidatus Liberibacter sp.' strain Okinama (T. Iwanami, unpublished results) (AB008366). The scale corresponds to $0.01 \%$ substitution.

\section{Sequence of the A2/J5 PCR fragment amplified from the $C$. capense liberibacter}

The sequence obtained after amplification with primers $\mathrm{A} 2 / \mathrm{J} 5$ from the $C$. capense bacterium (GenBank accession no. AF248498) was aligned with the corresponding sequence of 'Candidatus Liberibacter africanus'. This indicated that the sequences were similar and, when the sequence from the $C$. capense bacterium was aligned with those in the NCBI databases, the nearest sequences were those of the liberibacter species. However, the sizes of the amplified products were different: 669 bp for ' Candidatus Liberibacter africanus', 703 bp for 'Candidatus Liberibacter asiaticus' and $688 \mathrm{bp}$ for the liberibacter present in 


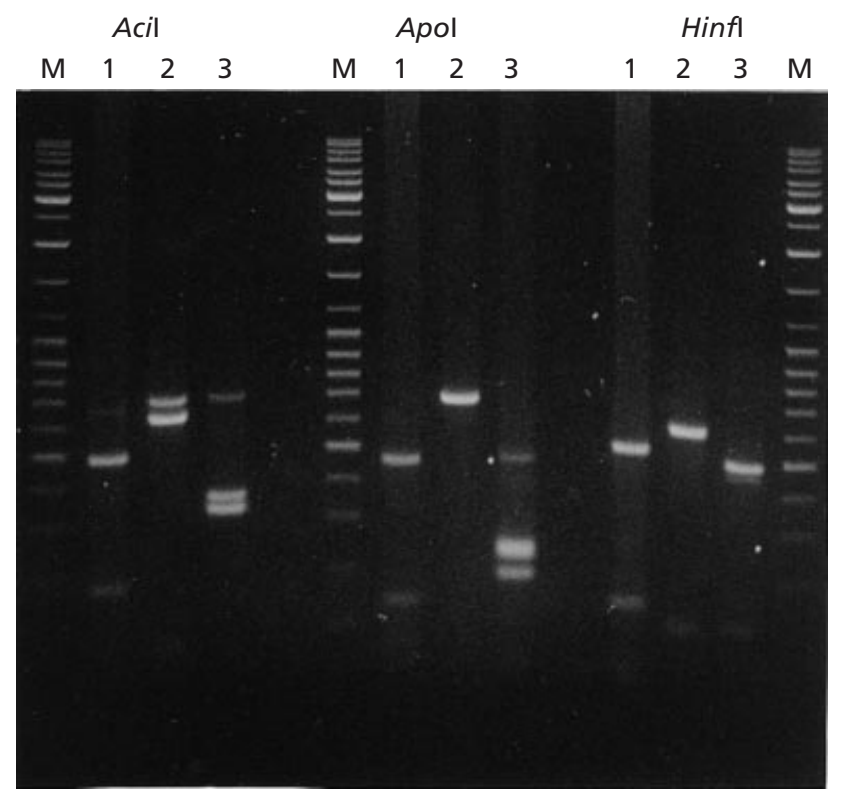

Fig. 2. Restriction enzyme analysis on $2.5 \%$ agarose gels of DNAs amplified with primers A2/J5 from symptomatic $C$. capense leaf extracts (lanes 2), and extracts of citrus leaves infected with 'Candidatus Liberibacter africanus' (lanes 1) and 'Candidatus Liberibacter asiaticus' (lanes 3). Lane M, $1 \mathrm{~kb}$ size marker (MBI, Fermentas).

C. capense. The latter had, in particular, an insertion of $25 \mathrm{bp}$ compared to 'Candidatus Liberibacter africanus'.

Fig. 2 shows that the three liberibacters (lane 1, 'Candidatus Liberibacter africanus'; lane 2, C. capense liberibacter; lane 3, 'Candidatus Liberibacter asiaticus') could be distinguished by restriction enzyme digestions of the amplified DNA with ApoI, AciI or HinfI. The fragments obtained were of the sizes expected, according to each sequence.

A 24-mer oligonucleotide, CAL1 (5'-GATTCGTAGAGGTGTTTTTTGAGG-3') at position 101-124, partially overlapping the $25 \mathrm{bp}$ deletion of 'Candidatus Liberibacter africanus', was defined on the sequence of the $C$. capense liberibacter. When used as a primer in association with primer $\mathrm{J} 5$ in a 35 cycle $\mathrm{PCR}$ reaction $\left(92{ }^{\circ} \mathrm{C}\right.$ for $20 \mathrm{~s}, 62^{\circ} \mathrm{C}$ for $20 \mathrm{~s}$ and $72{ }^{\circ} \mathrm{C}$ for $40 \mathrm{~s}$ ), amplification was obtained with the DNA extracted from infected C. capense leaves (Fig. 3, lanes 6 and 7) but not with DNA extracted from citrus leaves infected with 'Candidatus Liberibacter africanus' or 'Candidatus Liberibacter asiaticus' (Fig. 3, lanes 3 and 4). No amplification was obtained with water, DNA from healthy citrus or DNA from healthy C. capense (Fig. 3, lanes 1, 2 and 5, respectively). The size of the amplified DNA from infected $C$. capense leaves was $588 \mathrm{bp}$, as expected from the sequence.

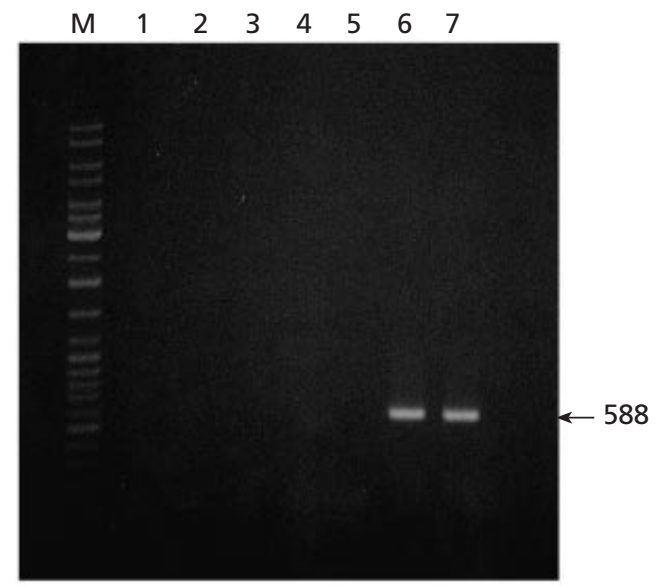

Fig. 3. Agarose gel electrophoresis of DNAs amplified with primers CAL1/J5 from water (lane 1), midrib-extracts from healthy citrus (lane 2) or C. capense (lane 5), citrus infected with 'Candidatus Liberibacter africanus' (lane 3) or 'Candidatus Liberibacter asiaticus' (lane 4), and symptomatic C. capense (lanes 6 and 7).

\section{Comparison of the intergenic 16S-23S rDNA region of the liberibacters}

To further compare the $C$. capense liberibacter to the known liberibacter species, the $16 \mathrm{~S}-23 \mathrm{~S}$ rDNA intergenic region was amplified with primers OI2 and 23S1 as described by Jagoueix et al. (1997), cloned and sequenced. When compared to the $16 \mathrm{~S}-23 \mathrm{~S}$ intergenic region of 'Candidatus Liberibacter africanus' and 'Candidatus Liberibacter asiaticus', sequence homology was higher with 'Candidatus Liberibacter asiaticus' (80.62\%) than with 'Candidatus Liberibacter africanus' $(66.2 \%)$. This is due to the fact that two tRNAs, those for isoleucine and alanine, were present in the intergenic region of both 'Candidatus Liberibacter asiaticus' and the $C$. capense liberibacter, whereas only one tRNA (alanine) has been shown in 'Candidatus Liberibacter africanus' (Jagoueix et al., 1997).

\section{Sequence of the PCR fragment amplified with primers 1897/1898 from the C. capense liberibacter}

Primers $1897 / 1898$, originally designed on the sequence of the rplKAJL-rpoBC operon of 'Candidatus Liberibacter asiaticus' (Planet et al., 1995, Villechanoux et al., 1993) allowed amplification of a $1.7 \mathrm{kbp}$ fragment of the equivalent operon of ' Candidatus Liberibacter africanus'. This fragment comprises, at the $5^{\prime}$ end, the intergenic region between ribosomal proteins $\mathrm{A}$ and $\mathrm{J}$ and, at the $3^{\prime}$ end, the intergenic region between the ribosomal protein $\mathrm{L}$ and the $\beta$ subunit of RNA polymerase (Villechanoux et al., 1993). When used to amplify DNA extracted 
Table 1. Homology (\%) between genes in the $\beta$ operons of the liberibacters

\begin{tabular}{|lccc|}
\hline Gene & $\begin{array}{c}\text { L. asiaticus/ } \\
\text { L. africanus }\end{array}$ & $\begin{array}{c}\text { L. africanus/ } \\
\text { C. capense bacterium }\end{array}$ & $\begin{array}{c}\text { L. asiaticus/ } \\
\text { C. capense } \text { bacterium }\end{array}$ \\
\hline 3' end of $r$ plA & $93 \cdot 5$ & $96 \cdot 8$ & $96 \cdot 8$ \\
Intergenic region A/J & $55 \cdot 4$ & $58 \cdot 9$ & $67 \cdot 8$ \\
$r p l J$ & $80 \cdot 8$ & $82 \cdot 1$ & $76 \cdot 8$ \\
Intergenic region J/L & $61 \cdot 4$ & $78 \cdot 1$ & $78 \cdot 0$ \\
$r p l L$ & $80 \cdot 1$ & $82 \cdot 0$ & $82 \cdot 3$ \\
Intergenic region L/B & $65 \cdot 9$ & $80 \cdot 9$ & $71 \cdot 4$ \\
5' end of $r p o$ B & $89 \cdot 8$ & $90 \cdot 6$ & $87 \cdot 8$ \\
Total homology & $79 \cdot 3$ & $82 \cdot 1$ & $79 \cdot 9$ \\
\hline
\end{tabular}

from symptomatic $C$. capense leaves, genes in the $r p l K A J L-r p o B C$ operon could also be amplified. Table 1 shows the percentage of homologies between the various coding or intergenic regions amplified from the $C$. capense liberibacter and the corresponding sequences from 'Candidatus Liberibacter africanus' and 'Candidatus Liberibacter asiaticus'. The complete coding regions (rplJ and $r p l L$ ) have around $80 \%$ homology with both 'Candidatus Liberibacter africanus' and 'Candidatus Liberibacter asiaticus'. As expected, less homology was found within the intergenic regions. The overall sequence homologies of the C. capense liberibacter DNA were 82.1 and $79.9 \%$ with 'Candidatus Liberibacter africanus' and 'Candidatus Liberibacter asiaticus' DNAs, respectively. This is very similar to the degree of homology $(79 \cdot 3 \%)$ existing between the same operon from "Candidatus Liberibacter africanus' and 'Candidatus Liberibacter asiaticus'.

\section{Reaction of the C. capense liberibacter with mAbs prepared against several liberibacter strains}

To further compare the liberibacter of $C$. capense to those present in citrus, IF reactions with mAbs produced from immunizations with Asian (Poona, India and Fuzhou, China) and African (Nelspruit, South Africa) (Gao et al., 1993; Garnier et al., 1987) strains of the liberibacters were carried out. The only antibodies reacting with infected $C$. capense leaf midrib sections were those specific for 'Candidatus Liberibacter africanus' (results not shown).

\section{DISCUSSION}

Using primer pairs defined from ribosomal 16S rDNA or ribosomal protein gene sequences of the two liberibacter species associated with citrus HLB, the corresponding genes of a bacterium inducing HLBlike symptoms in an ornamental rutaceous tree, Calodendrum capense, in the Western Cape province of South Africa have been amplified. PCR and phylogenetic analysis demonstrated that this bacterium belongs to the genus 'Candidatus Liberibacter'. From the $16 \mathrm{~S}$ rDNA sequence and phylogenetic analysis, as well as from the results of serology, the $C$. capenseliberibacter appears to be more closely related to 'Candidatus Liberibacter africanus' than to 'Candidatus Liberibacter asiaticus'. However, the intergenic $16 \mathrm{~S}-23 \mathrm{~S}$ region was closer to that of 'Candidatus Liberibacter asiaticus'. Whether this is the result of the preferential amplification of only one of the two rDNA operons present in the liberibacter genomes, as was already discussed in a previous paper (Jagoueix et al., 1997) remains to be established. Indeed, the two liberibacter species contain each at least two ribosomal operons. Up to now, an intergenic $16 \mathrm{~S}-23 \mathrm{~S}$ region containing only tRNA (alanine) from 'Candidatus Liberibacter africanus' and an intergenic $16 \mathrm{~S}-23 \mathrm{~S}$ region containing two tRNAs (alanine and isoleucine) from 'Candidatus Liberibacter asiaticus' have been amplified. Thus, it is not known if the two operons of each species have identical 16S-23S intergenic regions.

In the absence of a culture, it is difficult to give a bacterium a species or subspecies status. The classification of the liberibacter from Africa and Asia, into two different species, was based in particular on the genomic differences observed between the conserved $\beta$ operons of the two bacteria. Indeed, the homology of only $79 \cdot 3 \%$ suggested that the overall homology of their entire genome was likely to be under $70 \%$, the limit which defines species (Wayne et al., 1987). The $\beta$ operon genes of the $C$. capense liberibacter share a similar percentage of homology $(79.9 \%)$ with those of 'Candidatus Liberibacter asiaticus' showing that it belongs to a different species. The homology with 'Candidatus Liberibacter africanus' is higher ( $82.1 \%)$ and, interestingly, $\mathrm{mAbs}$ specific for 'Candidatus Liberibacter africanus' react with the Cape chestnut liberibacter suggesting that they are closely related. Indeed, within the 'Candidatus Liberibacter asiaticus' species, in which no genomic differences have been observed within the $16 \mathrm{~S}$ rDNA or $\beta$ operon sequences, six serogroups have been identified. In India, different liberibacter serotypes can be found in orchards that are separated by only a few kilometres. In South Africa, as of today, only one serotype has been found 
and the $C$. capense liberibacter, in spite of the genomic differences with the liberibacter found in Citrus, belongs to the same serogroup. The above results indicate that the bacterium infecting Cape chestnut belongs to the species 'Candidatus Liberibacter africanus'. However, it is proposed to give this liberibacter a subspecies status as it can be easily distinguished from the 'Candidatus Liberibacter africanus' species infecting Citrus by RFLP analysis of the amplified DNA or using the specific oligonucleotide CAL1.

PCR experiments with primers CAL1/J5 on DNA extracted from several HLB-affected citrus trees grown in the Western Cape area of South Africa and in particular from the orchard adjacent to the infected $C$. capense tree were negative (results not shown). This should be further documented, but suggests that: (i) the $C$. capense liberibacter is not (yet?) present in citrus; (ii) it is closely associated with the ornamental rutaceous tree; and (iii) it does not seem to be involved in the HLB outbreak in the Western Cape. The PCR method with primers CAL1/J5 can now also be used to determine whether the citrus psyllid $T$. erytreae is infected with the $C$. capense liberibacter and whether transmission to citrus is possible.

Because of the genomic and serological properties of the liberibacter from C. capense, it is proposed that this bacterium be assigned a subspecies status with the following designation: 'Candidatus Liberibacter africanus subsp. capensis' $[(\alpha-$ Proteobacteria $) \mathrm{NC}$; $\mathrm{G}-\mathrm{F}$; NAS (GenBank accession no. AF137368), oligonucleotide sequence complementary to unique region of the ribosomal protein operon 5'-GATTCGTAGAGGTGTTTTTTGAGG-3', S (Calodendrum capense, phloem); M].

\section{ACKNOWLEDGEMENTS}

We thank Capespan for financial support and facilities, and CIRAD-FHLOR for general support of the work on Huanglongbing. We thank Lise Korsten (University of Pretoria) for her help in PCR testing in South Africa.

\section{REFERENCES}

Aubert, B., Garnier, M., Cassin, J. C. \& Bertin, Y. (1988). Citrus greening disease survey in eastern and western African countries south of Sahara. In Proceedings of the 10th Conference of the International Organization of Citrus Virologists, pp. 231-237. Edited by L. W. Timmer, S. M. Garnsey \& L. Navarro. Riverside, CA: University of California.

Bové, J. M., Calavan, E. C., Capoor, S. P., Cortez, R. E. \& Schwarz, R. E. (1974). Influence of temperature on symptoms of California stubborn, South African greening, Indian citrus decline and Philippines leaf mottling diseases. In Proceedings of the 6th Conference of the International Organization of Citrus Virologists, pp. 12-15. Edited by L. G. Weathers \& M. Cohen. Riverside, CA: University of California.

Da Graça, J. V. (1991). Citrus greening disease. Annu Rev Phytopathol 29, 109-136.
Gao, S., Garnier, M. \& Bové, J. M. (1993). Production of monoclonal antibodies recognizing most strains of the greening BLO by in vitro immunization with an antigenic protein purified from the BLO. In Proceedings of the 12th Conference of the International Organization of Citrus Virologists, pp. 244-249. Edited by P. Moreno, J. V. Da Graça \& L. W. Timmer. Riverside, CA: University of California.

Garnier, M., Martin-Gros, G. \& Bové, J. M. (1987). Monoclonal antibodies against the bacterial-like organism associated with citrus greening disease. Ann Inst Pasteur/Microbiol 138, 639-650.

Garnier, M., Bové, J. M., Cronje, C. P. R., Sanders, G. M., Korsten, L. \& Le Roux, H. F. (1999). Presence of 'Candidatus Liberobacter africanum' in the Western Cape province of South Africa. In Proceedings of the 14th Conference of the International Organization of Citrus Virologists. Edited by J. V. Da Graça, R. F. Lee \& R. K. Yokomi. Riverside, CA: University of California (in press).

Hocquellet, A., Toorawa, P., Bové, J. M. \& Garnier, M. (1999). Detection and identification of the two 'Candidatus Liberobacter sp.' associated with citrus huanglongbing by PCR amplification of ribosomal protein genes of the beta operon. Mol Cell Probes 13, 373-379.

Jagoueix, S., Bové, J. M. \& Garnier, M. (1994). The phloemlimited bacterium of greening disease of citrus is a member of the $\alpha$ subdivision of the proteobacteria. Int J Syst Bacteriol 44, 379-386.

Jagoueix, S., Bové, J. M. \& Garnier, M. (1996). PCR detection of the two liberobacter species associated with greening disease of citrus. Mol Cell Probes 10, 43-50.

Jagoueix, S., Bové, J. M. \& Garnier, M. (1997). Comparison of the $16 \mathrm{~S} / 23 \mathrm{~S}$ ribosomal intergenic regions of 'Candidatus Liberobacter asiaticum' and 'Candidatus Liberobacter africanum', the two species associated with citrus huanglongbing (greening) disease. Int J Syst Bacteriol 47, 224-227.

Lapage, S. P., Sneath, P. H. A., Lessel, E. F., Skerman, V. B. D., Seeliger, H. P. R. \& Clark, W. A. (editors) (1992). International Code of Nomenclature of Bacteria (1990 Revision). Bacteriological Code. Washington, DC: American Society for Microbiology.

McLean, A. P. D. \& Oberholzer, P. C. J. (1965). Citrus psylla, a vector of the greening disease of sweet orange. $S$ Afr J Agric Sci 8, 297-298.

Moran, V. C. (1968). The development of the citrus psylla, Trioza erytreae (Del Guercio) (Homoptera: Psyllidae), on citrus limon and four indigenous host plants. J Entomol Soc $S$ Afr 31, 391-402.

Murray, R. G. E. \& Schleifer, K. H. (1994). Taxonomic notes: a proposal for recording the properties of putative taxa of procaryotes. Int J Syst Bacteriol 44, 174-176.

Oberholzer, P. C. J., Von Staden, D. F. A. \& Basson, W. J. (1965). Greening disease of sweet orange in South Africa. In Proceedings of the 3rd Conference of the International Organization of Citrus Virologists, pp. 213-219. Edited by W. C. Price. Riverside, CA: University of California.

Planet, P., Jagoueix, S., Bové, J. M. \& Garnier, M. (1995). Detection and characterization of the African citrus greening liberobacter by amplification, cloning and sequencing of the rplKAJL-rpoBC operon. Curr Microbiol 30, 137-141.

Trüper, H. G. (1999). How to name a prokaryote? Etymological considerations, proposal and practical advice in prokaryote nomenclature. FEMS Microbiol Rev 23, 231-249. 
Van de Merwe, A. J. \& Andersen, F. G. (1937). Chromium and manganese toxicity. Is it important in Transvaal citrus greening? Farming S Afr 12, 439-440.

Villechanoux, S., Garnier, M., Laigret, F., Renaudin, J. \& Bové, J. M. (1993). The genome of the non-cultured, bacterial-like organism associated with citrus greening disease contains the
nusG-rplKAJL-rpoBC gene cluster and the gene for a bacteriophage type DNA polymerase. Curr Microbiol 26, 161-166.

Wayne, L. G., Brenner, D. J., Colwell, R. R. \& 9 other authors (1987). International Committee on Systematic Bacteriology. Report of the ad hoc committee on reconciliation of approaches to bacterial systematics. Int J Syst Bacteriol 37, 463-464. 